This PDF is a selection from an out-of-print volume from the National Bureau of Economic Research

Volume Title: The Rate and Direction of Inventive Activity: Economic and Social Factors

Volume Author/Editor: Universities-National Bureau Committee for Economic Research, Committee on Economic Growth of the Social Science Research Council

Volume Publisher: Princeton University Press

Volume ISBN: 0-87014-304-2

Volume URL: http://www.nber.org/books/univ62-1

Publication Date: 1962

Chapter Title: The Supply of Inventors and Inventions

Chapter Author: Fritz Machlup

Chapter URL: http://www.nber.org/chapters/c2116

Chapter pages in book: (p. 143 - 170) 


\title{
The Supply of Inventors and Inventions
}

\author{
FRITZ MACHLUP \\ PRINCETON UNIVERSITY
}

THE word "supply" customarily has two different meanings: it means either a quantity actually made available or a schedule of quantities hypothetically made available as a function of one or more independent variables, particularly as a function of the price offered for the good or service in question while other conditions are assumed to be unchanged. In the following discussion of the supply of inventions, supply is to be understood in the second sense: it refers to hypothetical variations in the flow of new inventions becoming available for eventual industrial application in response to variations in the compensation society offers to those who undertake the production of inventions.

Lest we expect from this analysis more than it can yield, we shall note that even the best clues it may afford concerning the flow of inventions would help us toward only a very partial understanding of the determinants of realized technical progress. For, ordinarily, the tempo of effective advance in the productivity of resources will be determined by other things besides the supply of new inventions; in particular, by the rate of actual innovation, which does not depend solely on the rate of invention, and by the rate of the general adoption or imitation of improved technologies, which may be the most decisive variable involved. However, awareness of the fact that answers to many questions are needed does not make any one of them superfluous.

The analysis of the supply of inventions divides itself logically into three sections: (1) the supply of inventive labor - the chief input for the production of inventions; (2) the input-output relationshipthe technical "production function" describing the transformation of inventive labor into useful inventions; and (3) the supply and cost of useful inventions - the output obtained from the use of inventive labor. All this, of course, follows the pattern by which the supply of any economic good is analyzed in modern economic theory. 


\section{The Supply of Inventive Labor}

No unambiguous numerical estimates of the elasticities of supply of inventive talent and effort over substantial ranges can be derived from any data now available or likely to become available in the foreseeable future. Very general statements will have to do for our present purposes. What is needed here are educated guesses, intelligent judgments about the relative scarcity of the supply of qualified personnel and the possibilities of new recruitment and of increased efforts on the part of a given work force.

\section{WHY INVENTORS INVENT}

Why inventors invent; what nonpecuniary motivations they may have; whether pecuniary returns are necessary to secure inventive effort beyond a point; whether the size of the pecuniary returns significantly influences the amount of effort devoted to inventive activity; whether increased lucrativeness of inventing attracts proportionately increased personnel; whether increased personnel and increased efforts are likely to yield proportionately increased inventive capacity - these are some of the questions to be examined.

Inventions are sometimes made by accident, not as a result of special purposive efforts. But since even an accidental invention calls for some work - at least for its formulation or description-we may regard inventing as a special effort of labor, capital, and enterprise, and inquire into the motivations behind the expenditure of this effort.

Without trying to present an exhaustive list, we distinguish (1) inventing for fun, (2) inventing for fame, (3) inventing for the service of mankind, and (4) inventing for money. Perhaps we should add (5) inventing as an expression of the "instinct of workmanship"1 or of the "instinct of contrivance."

There are those who would not see much difference between exertion "for the fun of it"- motive 1-and exertion for the sake of "getting the job done"-motive 5. From a psychological and sociological point of view the difference is perhaps significant. But from the point of view relevant to this analysis, the inventor who enjoys every minute of his activities - as a game or sport, as it were-and the

\footnotetext{
${ }^{1}$ Thorstein Veblen, "The Instinct of Workmanship and the Irksomeness of Labour," American Journal of Sociology, September 1898, pp. 187-201. Id., The Instinct of Workmanship and the State of the Industrial Arts, New York, Macmillan, 1914.

${ }^{2}$ Frank W. Taussig, Inventors and Money-Makers, New York, Macmillan, 1915, p. 17.
} 
inventor who takes pains toiling and sweating over the problems which his instinct of workmanship dictates that he solve, have in common that they ask nothing in return for their efforts.

The only return expected by the person who exerts himself inventing in order to serve humanity-motive 3- is the successful completion of his projects and the feeling that this will contribute to social progress and the happiness of man. The return expected by the fame seeking inventor - motive 2-does not cost society much, because the recognition which it can show for the valuable inventions, the honors which it can bestow upon the great inventor, do not absorb any part of its productive capacity or of its national product, no matter how much productivity may increase as a result of the new inventions. (There will of course be a social cost measured by the alternative uses of the inventors' time and effort. But we are discussing here the compensations received by the inventors.)

The inventors who do their work as amateur sportsmen, workmanlike professionals, applause-seeking stars, or high-minded public servants require no money rewards-though they may be willing or even anxious to accept pecuniary advantages if such are given to other inventors under the institutional arrangements adopted by society. Any income they derive from their inventive activity is, therefore, in the nature of pure economic rent, that is, a payment not needed to call forth their efforts. What part of all inventive activity undertaken in our society is actually of this variety is anybody's guess. It may be only an insignificant fraction of the total inventive effort or it may be a substantial portion, at least of the labor effort of the highest qualities of inventive personnel. Certainly it cannot be the whole, simply because, if for no other reason, most people could not afford to spend much of their time on inventive work if it did not pay. Thus, undoubtedly some part of the labor devoted to the production of new inventions is supplied only in consideration of the pecuniary compensation that is held out to such labor. ${ }^{3}$

Beyond a certain point, the supply of inventive effort will depend on the offer (or hope) of pecuniary compensation. Thus, the supply

\footnotetext{
${ }^{3}$ Polled by questionnaire, 710 individual inventors reported on their motivation: 193 of them listed "love of inventing," 189 listed "desire to improve;" as against these 382 amateurs, sportsmen, and idealists, only 167 answered that "financial gain" had been their motive. But in answer to a different question, 265 of the 710 inventors, or 38.2 per cent, reported that they were earning their livelihood by inventing. See Joseph Rossman, "The Motives of Inventors," Quarterly Journal of Economics, 1931, pp. 522, 526.
} 
curve will start rising. Will this rise be gentle or abrupt? How elastic will the supply of inventive labor be once it becomes a function of pay? A judicious answer first requires that we distinguish among the concepts of labor force, labor time, labor energy, labor quality, and labor effectiveness.

\section{EXTRA EFFORT AND OVERTIME}

Although the distinction between labor time and labor energy is relevant for many problems, we need not complicate our argument, and may assume that the labor energy expended per hour will not be affected by the amount of compensation.

The distinction between labor force and labor time is relevant because there may be some elasticity in the supply of inventive labor merely because of changes in the number of hours worked per man. This would be socially significant because an increase in inventive labor, to the extent that it is only at the expense of people's leisure, would not encroach upon alternative productive activities. Persons with a bent for tinkering and inventing, busy with other jobs during their regular hours, may be willing to devote more of their free evenings and week-ends to inventive activity. Scientists and engineers employed in research and development may be willing to work overtime. But, however important that possibility might be in times of emergency for the implementation of "crash programs" in research and development, long-run programs designed for "progress in general" cannot successfully be based on the continuous and continual supply of overtime labor. The other source of supply of extra labor hours-the spare time of amateur researchers and tinkererscan possibly be drawn upon regularly. (To have mobilized these individual inventors is perhaps one of the achievements of the patent system in times past.) But it is a very limited source of supply, probably fully exhausted in the earliest phase of the rising supply curve of inventive labor. We may conclude that the possible sacrifice of leisure cannot be counted on to provide substantial amounts of labor for additional inventive activity; and it will therefore be no serious mistake to think of new recruitments to the inventive labor force, diverting labor from other occupations, as the only significant element in the elasticity of supply of inventive labor.

Thus, when we speak of the supply of inventive labor we shall not stop to differentiate between the size of the inventive labor force and 
the amounts of time and energy expended per man but shall simply think of the total amount of inventive labor as some number of men (or man-hours); indeed we shall, for the sake of simpler expression, use the term inventive labor force as equivalent to the total effort devoted to the search for inventions.

\section{QUALITY DIFFERENCES AND NEW RECRUITMENT}

We must not, however, neglect differences in labor quality; they are particularly important in the case of researchers and inventors. It would seem that the blend of training, experience, originality, tenacity, and perhaps genius which makes a man a potentially successful inventor is too "special" to permit the economic theorist to make his customary assumption of "homogeneity of productive resources"unless he has very good excuses. Whether his trick of translating different qualities into one standard quality ("efficiency units" or "corrected natural units") can serve a good purpose here, will have to be examined. Off hand, a statement that five hours of Mr. Doakes' time were the equivalent of one hour of Mr. Edison's or two hours of $\mathrm{Mr}$. Bessemer's would sound preposterous. But if such "misplaced concreteness" is avoided, the device may prove helpful in abstract arguments.

Inasmuch as the problem of differences in the quality of inventive talent concerns us chiefly in connection with new recruits to the inventive labor force, the speed with which the recruitment is to be accomplished will be an important consideration. The time element is always significant in elasticity problems; it is particularly so regarding entry into an occupation such as "inventing", for which training and experience are essential.

A distinction between the short run and the long run is the customary device for focusing attention on important differences in the length of time allowed for certain reactions to given changes. Present membership in the labor force may be made the criterion for the distinction between short-run and long-run supply of inventive labor. The short-run supply curve would then depict the rates of compensation necessary to secure an expansion of the inventive work force through transfers from other fields and occupations; the long-run supply curve would depict the rates at which an expansion can be secured through both transfers of persons already in the labor force 
and recruitment of persons entering the labor force for the first time. ${ }^{4}$

The short-run supply function of inventive labor expresses the ease or difficulty of drawing on trained, though probably less experienced, personnel; for the most part, these will be persons now engaged in teaching or fundamental research who can be induced to switch to applied research and development work. The long-run supply function must reflect consideration of the teaching capacity of the universities and institutes of technology, and of the pool or flow of potentially qualified students. Obviously, the elasticity of the long-run supply is greater than that of the short-run supply; it will be largely a matter of letting public knowledge of job openings and of differential earnings potentials steer young students into the natural science and engineering departments of the institutions of higher education. The question is whether, in both the long run and the short, additions to a given amount of inventive labor-additions in response to higher payare apt to be of lower quality.

\section{The Short-Run Supply}

Some of the clues that come to mind when one reflects on the question of quality differences in connection with the short-run supply of inventive labor seem to be contradictory. There is the case of the academic scientist who, bribed into industrial research, out-invents the most seasoned inventors. The success stories of former university professors as salaried inventors employed in industrial research and development work may be presented as evidence in support of an argument that the quality of new members of the inventive labor force need not be below the previous average, and may even be above itat least as long as there are still professors that can be lured from their academic posts. (This reservation is significant; it shows again that much depends on where one "starts" adding to the force already employed, that is, on how many more researchers can be obtained in further raids on college and university faculties.) The validity of the evidence, however, may be questioned on several grounds: that the cases cited were exceptions to the rule; that many of the new members

\footnotetext{
${ }^{4}$ It is convenient to think of the new entrants into the labor force as equal in number to those leaving the labor force through death or retirement. This simplification is designed to separate the problem of allocation from the problem of population growth. This does not mean that a long-run supply curve of this sort will be less relevant in an analysis of the allocation problem of a growing total labor force; but the supply curve of any particular kind of labor would have to be in terms of percentage shares of the growing labor force. For the sake of simpler expression it is customary to discuss resource allocation under the assumption of a given labor force, even for the long run.
} 
of industrial research staffs had previously been engaged in inventive work of a more fundamental nature and that their transfer from academic to industrial positions was in fact not a net addition to the inventive work force; that many of these transfers were made in response, not to the lure of money, but to appeals to undertake tasks of immediate usefulness in a national emergency.

The opposite contention can also be defended; that as a rule the qualifications of new transfers to the inventive work force will be inferior to those of persons who have entered it earlier for less pay. Such an argument may be based on rather broad generalizations about "typical" human attitudes: that ordinarily people prefer to do things they are good at. The person who prefers to teach or write, and who will only by much higher rates of compensation be attracted to the engineer's draftboard or the industrial laboratory, is probably less qualified for inventive work than the "tinker and contriver" who follows an almost irresistible drive to find and try new devices. Regardless of whether more weight is given to deductions from such speculative assumptions or to inductive generalizations from individual observations, one will have to yield to the common-sense judgment that a point must exist beyond which further transfers to the research and development work force cannot possibly be of the same quality. The number of trained people in the labor force is limited and if research and development staffs are to be expanded close to that limit or beyond it, less qualified persons will have to be included.

\section{The Long-Run Supply}

Regarding the long-run supply of inventive labor, is there any presumption that those who are attracted only by higher rates of pay are less qualified than those willing to work for less? Youngsters, at the time when they choose their professional training, may not yet have developed preferences consistent with their aptitudes. They may have a preference for one thing but superior aptitude for another. Better earnings prospects might then bring into the field young people not less qualified than those who would have chosen it even with poorer earnings prospects. If this should be a valid argument in speculating about the long-run supply of inventive labor, it certainly cannot be valid for unlimited amounts of labor. For in calculations of the potential supply of inventive labor, innate ability undoubtedly counts as much as training, if not much more. The popular hero worship for inventors may grossly exaggerate the scarcity of inventive genius but 
to suppose that mere training can produce any desired amounts of inventive capacity is a worse exaggeration in the opposite direction. One may, of course, steer more young people toward inventive work, but one must not expect them all to be of equal caliber.

If additional personnel is attracted to the inventive labor force only by higher rates of compensation and if, by and large, the newcomers are less qualified than those who are willing to work for less, the elasticity of the "effective supply" of inventive labor is held down by both factors, preference and aptitude. If the supply of inventive labor expressed in terms of natural units (man-hours) is not very elastic, it will certainly be still less elastic if expressed in terms of units corrected for differential qualification. ${ }^{5}$

Higher rates of pay (or expected pay) might, at some point, call forth hardly any more inventors, but merely more associate inventors and assistant inventors, that is, talents not apt to produce independently, but only to assist the leading men, taking off their shoulders some of the work that can be assigned, and thus releasing some of their time and thought for the really creative tasks. The aggergate capacity to produce new inventions can thus be increased through additions to the inventive labor force, regardless of whether the additional men are working independently of or in collaboration with those previously at work. ${ }^{6}$ But the addition of thousands of hours of work of assisting specialists (engineers, researchers, etc.) may mean merely hundreds of hours added to really inventive activity or capacity, ${ }^{7}$ and the latter can therefore be expanded only at a greatly increased money cost.

This does not say anything about the prospect that increased amounts of inventive talent put to work will actually produce new inventions in proportionately increased amounts. The supply we have been discussing is merely that of talent and effort ready to be put to

\footnotetext{
${ }^{5}$ The technique of "corrected natural units" is used here only as an analogy, not as a measuring device. A supply curve in terms of "corrected natural units" is not only less elastic than a supply curve in natural units but also smaller (to the left of it) over at least a part of its course.

${ }^{8}$ In a sense, another errand boy hired for an industrial research laboratory would be an addition to the inventive labor force inasmuch as he may enable the staff to work with fewer interruptions. However, if we go that far in expanding the concept of "inventive labor", some of our earlier generalizations concerning its supply in terms of natural units would lose validity. It is preferable to confine the concept to the professional personnel.

7 "The real moving spirits are few and the rest pedestrian, although of course useful, supporters. Quantity cannot make up for quality and little purpose is served in lamenting the absence of what are in fact unattainable levels of intellectual coordination when there are always too few minds of the highest calibre and there is a limit to the help that can be afforded them in their original thinking." John Jewkes, David Sawyers, and Richard Stillerman, The Sources of Invention, London, Macmillan, 1958, p. 162.
} 
work-the input, not that of the actual product of this talent and effort-the output, in the form of workable inventions.

\section{THE SOCIAL COST OF THE ADDITIONAL LABOR IN INDUSTRIAL RESEARCH}

The additional money outlay required to secure a small addition to the inventive labor force is no fair indication of the social cost involved. The money outlay includes the surplus, or rent, accruing to inventive personnel who would have been willing to work for less than the rate of compensation that is actually paid in order to attract more people to research and development work. These rent payments do not themselves signify the use of more resources; and only the cost of additional resources, in terms of alternatives foregone, constitutes a social cost. The increased rent payments are merely transfers of income from one part of society to another; they are losses to "society exclusive of inventive personnel," and gains for the members of the "inventive labor force" (who are of course part of "society as a whole").

The social cost of inventions is determined by the value of the most valuable alternative output that could be produced with the same input. But the price paid for any sort of input will reflect the social value of its potential output only where the resources are acquired in competitive markets and where the market prices of all alternative outputs reflect their full contributions to economic welfare. It is very doubtful that these conditions are met in the case of the resources required for the production and development of inventions. With regard to the alternative uses of the resources, chiefly basic research and higher education, the social benefits resulting are far above any private benefits conferred on their "buyers." The market prices of education and basic research and the compensations paid to scholars are no more commensurate with the social value of the services rendered than the market prices of inventions and the compensations paid to inventors are with the social value of inventions. Thus, the compensations needed to attract additional labor into the business of inventing do not reflect the social values of education and basic research that are foregone by the transfer of personnel. ${ }^{8}$

${ }^{\mathbf{8}}$ For a preliminary discussion of the alternative costs of education, basic research, and industrial research, all competing for the same productive resources, see my article "Can There Be Too Much Research ?" Science, 1958, pp. 1320-25. A more detailed treatment, including relevant statistical information, will be found in "The Allocation of Scientific Personnel" a doctoral dissertation by Vladimir Stoikov, submitted to the Johns Hopkins University (May 1960). 


\section{The Production of Inventions}

To regard a study of the supply of inventive labor as a prerequisite of a study of the cost and supply of inventions is to assume that there is a quantitative relationship between the input of labor and the output of inventions. The implications are that inventions are "produced," that the volume of production can be measured or at least "sized up" to the extent necessary to make it meaningful to speak of an increase and a decrease in the flow of new inventions, and that changes in output depend on changes in input, at least partially. These assumptions should not be made without attempting to justify them.

One might take the position, and defend it on good grounds, that it is impossible even to define invention, let alone identify, count, or weight inventions for purposes of measuring the quantity produced by inventive effort. And if it is meaningless to quantify the output, it must be meaningless to assert or posit the existence of a quantitative relationship between input and output. Or, one might take a less negative position and grant the possibility of quantifying the inputs and outputs, at least roughly or merely for purposes of constructional reasoning, but at the same time hold that the incidence of accidents in making inventions is too great to legitimize, even provisionally, the assumption of a "production function," a functional relationship between input and output. These issues are discussed in other papers of this volume.

Assuming that it makes sense to quantify the input, i.e. inventive labor plus equipment and whatever else is needed, as well as the output, i.e. new technical inventions, will a model that assumes a functional relation between input and output be relevant in an interpretation of the real facts concerning the flow of inventions?

An affirmative answer-at least to the extent that an increase in input will, as a rule, produce an increase in output-is implied in the theory that invention can be "stimulated" by patent systems or subsidization. Even more than that is implied in the familiar arguments about the need or desirability of increased industrial research and development: they implicitly deny, on the one hand, that a very small increase in research will suffice to produce a vast increase in inventions and, on the other, that a huge increase in research will produce but a trivial increase in inventions. Thus there has always been an implicit acceptance of a sort of "production function" affirming a posi- 
tive correlation between input and output and expressing certain constraints which exclude extreme values of the input-output ratio.

These constraints have long been thought to apply only to the "invention industry" as a whole. For individual producers of inventions no functional dependence of output upon input seemed to hold: a most extravagant increase in input might yield no inventions whatsoever, and a reduction in inventive effort might by a fluke result in the output that had in vain been sought with great expense. As in a lottery, individuals would still make plans involving high stakes on the basis of a probability calculus that applied only to the whole population of gamblers, not to any single one. The making of inventions would be a lucky accident, nothing the individual firm could count on. The inventive process, however, has become more methodical than it used to be in earlier times, more systematic, mechanized, and routinized, ${ }^{9}$ until it now seems that the probability calculus applies to individual producers of inventions, even to medium- and small-scale establishments. ${ }^{10}$ All of the large firms and a good many smaller ones, in the industries in which technology has been advancing rapidly, regularly allocate funds for research and development, and one could hardly assume that they do so as a sheer gamble, without rational and reasonable expectations of a satisfactory return. They have learned that research expenditures can be profitable, and this implies that they expect inputs of inventive labor and complementary resources to produce workable new inventions.

All production functions involve probability distributions of some sort, with more or less wide deviations from the norm resulting from such factors as variations in the performance (speed, accuracy) of human operations, differences in the quality (purity, strength, consistence) of materials, unevenness in the operation (speed, accuracy) of tools and machines, fluctuations in the supply (quantity, pressure, tension) of energy, changes in weather (precipitation, humidity, sunshine, winds), etc. The deviations are notoriously great in agricultural

9 "The greatest invention of the nineteenth century was the invention of the method of invention." Alfred North Whitehead, Science and the Modern World, London, Macmillan, 1925, p. 120.

10 "In the larger firms of today, the flow of new ideas for product and process innovation results, not from the chance inspiration of exceptional individuals, but from a deliberate decision by management to spend money on research and development. There is still a great need for the inspiration of genius, but much routine discovery and improvement waits simply for the investment of sufficient resources." Charles F. Carter and B. R. Williams, Industry and Technical Progress: Factors Governing the Speed of Application of Science, London, Oxford University Press, 1957, p. 108. 
production, with its dependence on weather (rainfall, frosts), insects, fungi, etc. This does not prevent anybody from basing theoretical as well as practical considerations upon production functions for agricultural products. Both the individual farmer and the government adviser on farm policy assume for their plans-the former for his private production plan, the latter for some national program-that the use of more land, more seed, more fertilizer, and more labor would increase output by certain quantities. Perhaps there is less uncertainty in the production plan for an entire region or country than there is for an individual farm because of the likelihood that positive and negative deviations will cancel out in the larger "population."

That chance, luck, and accident play an unusually large role in the "invention industry" need not preclude the existence of sufficient regularities in the production of inventions to permit expression of the relationships in the form of production functions. What does, however, complicate matters in the invention industry is the extreme heterogeneity of the product as well as of the producing units. May one assume much similarity in the input-output relations that are relevant for individual inventors (self-employed free lancers), small teams of experts specializing in research and consultation work in particular fields, large independent or cooperative research laboratories, scientific or engineering departments of universities, governmental research agencies, and research and development divisions of large industrial concerns? Is it reasonable to expect much similarity in input-output relations in the inventive work in aeronautics, electronics, nuclear physics, chemical engineering, automotive mechanics, etc. ? Can one justify the assumption that there is some reasonably stable ratio of successful to unsuccessful tries in the mass of all inventive work with its uncertain composition?

To ask these questions is to suggest negative answers. Contrary to other industries where the probable errors are larger for individual producers than for the industry as a whole, the "invention industry" is apt to present smaller dispersions in the probability distributions for the individual producers. The individual firm undertaking inventive work in a certain field and attempting to solve some problems related to more or less circumscribed objectives is quite capable of setting out with fixed budgets, appropriations, and time schedules, that is, with a specification of the inputs believed necessary to achieve the goal, to produce the inventions wanted. This is true for the small independent research outfit (producing nothing but inventions) as 
well as for a research organization integrated with a firm that also produces other products, particularly the kind of product for which the wanted inventions would be most useful. But to develop a production function for "inventions in general" for the "invention industry as a whole" seems an impossible task, especially if nothing is said about what kinds of inventions are sought.

Such a disappointingly negative conclusion, however, implies an excessively literal interpretation of the term "production function." One need only remember the universally accepted proposition that "agriculture operates under diminishing returns" to realize that no definite, numerically specifiable production function for agricultural output is referred to in the context. Obviously, there cannot be one definite aggregate production function for a variable composite of barley, wheat, rye, corn, rice, cotton, tobacco, potatoes, carrots, spinach, and all the rest, produced on land of all grades and locations, by farms of all sizes. Yet, a statement concerning constant or diminishing returns in the agriculture of a certain country at a certain time makes perfectly good sense. The unit of output would be some "homogenized bushel of produce" and the shape of the production function would merely illuminate the general nature of such quantitative relationships as are relevant to the problem at hand. It is in this sense that one may speak of the invention industry and of its output, which evidently is not homogeneous but which can be "homogenized" for the sake of reasoning and discussion. To repeat, the production function of inventions in general in the invention industry as a whole is only an abstract construction designed to characterize some quantitative relationships which are regarded as empirically relevant.

THE RATE OF INVENTIVE OUTPUT IN THE ECONOMY AS

A WHOLE

What does the production function look like? Are there ranges of increasing and diminishing returns in the production of inventions in the economy as a whole? Is there an optimum point or range in the resource allocation to the "invention industry"? Is the total inventive effort in the economy more likely to be of such dimensions that it would be more efficient if it were expanded or if it were cut down? Not that efficiency in the production of inventions-that is, the smallest possible number of researchers and developers per inventionshould be regarded as an end in itself. If society were getting as many inventions per year as it wanted, it would be foolish to push for more 
just because this would raise the average output per inventive worker. Similarly, if the flow of inventions was inadequate and society wanted to increase it, it would be foolish to hold back just because the increase would lower the average per inventive worker. But, even if the possibility of improving the input-output ratio in the production of inventions (by expanding it under increasing returns or curtailing it under diminishing returns) cannot be a decisive factor in society's decision concerning the desired flow of inventions, it is nevertheless something to be taken into account.

Superficially it might appear that the question of increasing or decreasing returns to inventive effort in the economy as a whole is the same as, or related to, the frequently discussed question of the acceleration or retardation of the rate of invention in the course of time. There have been two schools of thought on the subject of the effect of the flow of inventions upon the ease of making further inventions. According to the "acceleration school," the more that is invented the easier it becomes to invent still more. This is deduced from the assumption that every new invention furnishes a new idea for potential combination with vast numbers of existing ideas; and from the mathematical proposition that the number of possible combinations increases geometrically with the number of elements at hand. According to the "retardation school," the more that is invented, the harder it becomes to invent still more. This is deduced from the assumption that there are limits to the improvement of technology. In its extreme form this thesis states that the more that has been invented the less there is left to be invented.

Although this issue concerning the historical-past or futurechange in the potential rate of technological progress will presently be shown to be irrelevant to the question of the potential returns to inventive effort at any particular time, it is worth while reflecting about it. There is no a priori reason why the possibilities of technological development should be either narrowly limited or virtually limitless. Nor is there any legitimate basis for inductive inferences from the relatively brief periods in which accelerated or retarded rates of inventive accomplishment were observed.

In periods of depression prophets of technological stagnation were usually listened to with greater attention, and repeatedly over the last hundred years persons recognized as authorities at the time told the world that all important inventions had already been made and no further inventions of great import could be expected. Such pessimistic 
predictions of the future of technological exploration look particularly comical to a reader who has the advantage of hindsight, for they were made before the automotive, electrical, radiomagnetic, and nuclear revolutions of technology had occurred. Thus the predictions were surely wrong at the time they were made. There is little inclination to accept such predictions as correct at the present.

Prophets of an ever-increasing flow of inventions have also been disappointed. Even if patent statistics (which show a drastic decline in patenting relative to the manpower employed in research and development) are rejected as a yardstick for the flow of inventions, no evidence has been presented to support the thesis that the rate of inventive accomplishment has been increasing relative to the size of the population, the labor force, or the inventive work force. There are indications that inventing is becoming increasingly expensive in terms of manhours. But this need not be taken as counterevidence to the assertion that inventing becomes easier over time; it may merely be indicative of overly intensive efforts to achieve too much in a short time. And this brings us back to the question of increasing and decreasing returns to inventive activity at a given time.

These are two essentially different issues: one refers to the shape of the production function (in the invention industry) at a certain time; the other refers to the shift of the production function in the course of time. In other words, increasing or diminishing returns relate to the production possibilities existing at a certain time; accelerating or decelerating rates of invention relate to changes in the production possibilities over time. In the former relationship the accomplishment per man is a function of the number of men employed while "time," with all environmental conditions, is unchanged; in the latter the accomplishment per man is a function of time while the number of men employed (in the invention industry) is unchanged (absolutely or relative to the labor force).

\section{THE LAWS OF RETURNS AND THE TECHNOLOGY OF PRODUCING TECHNOLOGY}

Increasing returns in the inventive work of a nation can prevail if the national scale of research is too small to permit sufficient division of labor among specialists and enough cross-fertilization between experts in different fields of knowledge. There may be such a thing as a balanced growth of knowledge that can be achieved only if the total amount of research is large enough for simultaneous work in many 
areas. If some of the frontiers of knowledge are not manned with sufficiently large forces, the progress of work along other sectors may be retarded. An increase in the total work force may then bring about a more than proportional increase in the rate of invention. This range of increasing returns is of course limited: as soon as the required minimum numbers of research workers are allocated to all areas of scientific and technological knowledge, further additions to the inventive work force can at best produce proportional increases in inventions.

As from time to time fundamental discoveries open up entirely new areas of research, development, and experimentation, the opportunities to produce new inventions may be radically improved and an inventive work force which had been large enough to extend far beyond the range of increasing returns may suddenly be too small to take advantage of the new opportunities. In other words, the new (or shifted) production function for inventions may be such that a given amount of inventive labor, previously operating under constant or diminishing returns, would be back in the range of increasing returns.

The possibility of diminishing returns in the invention industry may seem puzzling on first thought. The phenomenon of diminishing returns is always attributable to the presence of one or more fixed factors -factors necessary in production but not present in increased quantities when the input of variable factors is increased. The variable factors in the case before us are inventive labor plus the required facilities for research and experimentation (laboratory space, instruments and machines, materials, energy, administrative and clerical help). What are the fixed factors in the production of inventions?

In order to answer this question we must inquire a little into the technology of the production of technological inventions, which is a rather peculiar, bewildering business. In general, technology is the art of transforming certain materials into certain products, usually with the aid of certain kinds of equipment; in the production of inventions, however, technology is also the chief raw material and equipment, and it is the product, to boot. The inventor starts with technology, applies technology, and ends up with technology.

The process of inventing may be schematized as follows. First, the inventor is confronted with a problem, that is, with dissatisfaction about the ways certain things are done coupled with a feeling that there are better ways of doing them. Second, he tries to think of similar problems that have been solved before, which either are familiar to 
him or which he proceeds to study. This usually gives him clues for possible plans to be followed in the solution of his problem. Third, he carries out these plans, several of which may not work but may suggest other clues. Finally, he finds a solution. ${ }^{11}$ If this scheme describes the technology of problem solving and inventing, it also makes clear that, in the earlier steps, technology, the existing stock of scientific knowledge and knowledge of the industrial arts, enters as raw material and equipment, while in the end technology, an advance in the technical arts, emerges as the product of the inventive process.

Once the multiple role of technology in the inventive process is understood, it will not appear paradoxical if the existing stock of scientific knowledge and the state of the industrial arts at any moment of time is named as a fixed factor in the process of producing new inventions. The number of problems to be solved (the stock of known problems) is another factor fixed at any moment of time. If increasing amounts of variable factors-inventive labor effort with all the required facilities--are applied to a given amount of known problems and a given equipment of known technology, the increase in the amount of product in the form of technological advances will, beyond a point, be less than proportional.

\section{DIMINISHING RETURNS}

Increased amounts of inventive talent devoted to the search for solutions to given problems, and further drawing on the given stock of knowledge, will bring forth novel solutions in increased numbers but after some point the increase in output, in terms of solutions or inventions, will not be in proportion to the increase in input. An expansion of the number of research men working on the production of new knowledge would of course always be technically possible (in contrast to those kinds of production where the fixed factor is a tangible thing, such as land or machinery, and where men, beyond some number, would get in one another's way or could physically not get near the fixed factor). But the addition of more researchers, beyond some number, would imply duplication of effort, resulting not in more new solutions to open problems but in more frequent instances of simultaneous or nearly simultaneous arrivals by several inventors at similar solutions

${ }^{11}$ Cf. G. Polya, How to Solve It, Princeton University Press, 1948, passim. From this schematic description it ought to become obvious that a separation of the cost of failures from the cost of successful tries cannot reasonably be attempted. 
to identical problems. The output of new inventions might not be much increased.

Merely in order to guard against misunderstandings, it should be remembered (1) that diminishing returns in the production of inventions prevail not from the start, that is, not for small amounts of input of effort, but only after input has reached a certain point; and (2) that the point where diminishing returns set in is apt to be pushed up as the stock of existing knowledge grows, because the number of problems on which work may fruitfully be done is likely to increase with that growth.

Some economists with an exaggerated opinion of dynamic theory and an inadequate understanding of static reasoning might hold that the entire conception of diminishing returns is out of place in an area as intrinsically dynamic as the production of knowledge. Since any new discovery or invention changes the stock of knowledge as well as the stock of problems to be solved, what sense is there in assuming that knowledge and problems are fixed?

If some may have a hard time seeing the sense of such an assumption, an explanation must be provided even if it insults the intelligence of those to whom the point is obvious. The point is that an allocation of research personnel that will fit the research agenda of next year need not fit the agenda today. If the list of problems to be solved is apt to grow from today to next month, and still more to next year, this does not mean that it would serve any good purpose to employ a research staff too large for the present tasks. It may, of course, be wise to provide for a gradual increase in the research staff commensurate with the increase in the stock of problems to be solved. At any moment, however, the number of men used for inventive work may be such that the amount of duplication is moderate, substantial, or enormous. At any moment, in other words, the production of inventions may be pushed far into the range of diminishing returns, conceivably even into the range where marginal returns to inventive input are zero. If the manpower so lavishly employed is kept unchanged for some time, it is possible that the research agenda will grow to a point of parity with the oversized research outfit. This would not make the original overallocation of resources any more justifiable than it would be in any other industry: the expectation of growth, and therefore of growing manpower needs, does not warrant the employment of more labor than can be efficiently used at the time being.

Comprehension of this point is perhaps made more difficult by the 
realization that the technological horizon may rather suddenly be expanded by a fundamental discovery which shifts the production function for technical inventions most drastically. In view of this peculiar way in which the dynamic aspects of the growth of knowledge impinge on the relevance of static theorizing, it may be desirable to deal once more with the effects which discoveries and inventions may have upon the production of inventions.

\section{PROBLEM - RAISING SOLUTIONS}

Invention is the solution of a technological problem; but it is possible that in the course of solving a problem or as a result of solving it new problems are raised. Thus, an invention may fulfill a task and at the same time create more tasks. To be sure, not all inventions are of this sort. The solution of an old problem may leave less to be done, one item of the agenda having been checked off as completed. We may call such a solution an agenda-reducing invention. If a solution by raising new problems leaves more to be done than there had been before, we may call it an agenda-increasing invention or discovery.

Fundamental discoveries and basic inventions, by definition, open up new vistas and create new opportunities for further invention. Thus, one might be tempted to generalize and state that basic research will yield agenda-increasing discoveries while applied research will yield agenda-reducing inventions. This would, however, be an exaggeration. Industrial research of a definitely applied kind may result in inventions of considerable complementarity with solutions to new technical problems. Indeed, a relatively narrow invention may point to some previously unnoticed gap in basic knowledge and thus raise problems for fundamental research. And, more often, an invention of the mere gadget type may unexpectedly create the opportunitynay, the necessity-for scores of additional inventions.

Several writers have distinguished between two kinds of inventions: fundamental (basic, major, revolutionary, breakthrough, key) inventions and accessory (adaptive, minor, perfecting, improvement) inventions. Every fundamental invention creates an opportunity for many accessory inventions. Hence, the emergence of a fundamental invention is apt to change the input-output ratio of inventive effort, that is, the productivity of a given size of inventive labor force and the productivity of a given increase in the same. But the dichotomy is not the same as that between agenda-increasing and agenda-reducing inventions. Mere perfecting or improvement inventions may suggest 
possible combinations with other technological elements or possible applications to entirely different kinds of products, and thus be of the agenda-increasing type, leaving more, not less, to be done in times to come.

The predictions of acceleration or of retardation in the rate of invention, which we have mentioned above, reflect to some extent judgments about the relative frequencies of agenda-increasing and agenda-reducing inventions. But the conflict of recorded opinion is probably less serious than one may think. For it seems that several writers who assumed a prevalence of agenda-reducing inventions and predicted, therefore, a retardation in the rate of inventive achievements were thinking of particular industries or particular areas of technology. On the other hand, those who assumed a prevalence of agenda-increasing inventions and consequently predicted an acceleration of invention appear to have been thinking of the entire domain of technology. Retardation of invention in particular industries would be perfectly compatible with acceleration of invention in the economy as a whole.

For the economy as a whole, or for the entire domain of technology, the assumption of a prevalence of agenda-increasing inventions is probably more plausible. This does not, however, imply that the production function will necessarily shift upward in the sense that a given number of inventors will produce more inventions per unit of time. The continuing increase in the stock of technological problems to be solved, which is implied in the assumption of a prevalence of agendaincreasing inventions, will extend both the ranges of increasing and of diminishing returns to inventive personnel and, thus, allow a larger inventive work force to be employed without excessively wasteful duplication. But the enlargement of the agenda, the increase in the number of problems on which work can be done, need not increase productivity per research worker. Many of the new problems may be tougher than the older ones were. An increase in opportunities to invent need not mean that inventions become easier to make; on the contrary, they may become harder. In this case, there could be a retardation of invention despite the prevalence of agenda-increasing inventions and a continuing increase in inventive possibilities.

The hypothesis of the increasing difficulty of new technological problems would force abandonment of the homogenizing device proposed in the discussion of the quantification of invention. It may be permissible to speak of an output of inventions of average difficulty 
so long as one deals with the potential solutions of given technological problems worked upon by varying numbers of inventive personnel. But if one has to deal with the dynamic problem of changes, from period to period, in the state of knowledge and the stock of problems to be solved, then the homogenizing of the output of inventions becomes useless and even misleading.

If the separability of the static problem from the dynamic problem is conceded, if it is understood that the shift of the production function for inventions is one thing and its shape another, and if the implications of that shape for problems of resource allocation are realized, then the previously stated conclusion, that it is possible for society to devote such large amounts of productive resources to the production of inventions that additional inputs will lead to less than proportional increases in output, will no longer be questioned. Whether at any given moment the inventive labor force employed has actually reached the point of diminishing returns is a question for practical expert judgment.

In any event, even if we knew for certain that society had pushed its inventive efforts far into the phase of diminishing returns, we could not infer that it had gone too far. Similarly, the most certain knowledge that we were still far away from that phase would not provide sufficient reason for society to go more heavily into the business of inventing. After all, the evaluation of the physical cost of inventing is only a small part of the task of evaluating the economic or social net benefit of inventive work. But it is by no means irrelevant or unimportant to know that the cost of inventions in terms of physical inputs may be diminishing, constant, or increasing, depending on the circumstances, and also to know under what circumstances one might have to take account of the possibility that the cost is increasing at a forbidding rate.

\section{INVENTIONS SELECTED OR REJECTED FOR USE}

Not all new inventions turn out to be workable; not all that seem technically workable turn out to be commercially usable; and not all that might be commercially usable are actually used, many being rejected in favor of others that look more promising. As a matter of fact, the percentage of all new inventions actually put to practical use is very small indeed. ${ }^{12}$

12 "Invention is necessarily wasteful. When everything feasible has been done to plan research coherently, the uncertainty of the outcome, even of the less revolutionary 
Should only the inventions selected for use or the rejected as well be counted in the quantity of inventions produced? One may wish to follow the practice of other industries in reporting total output, and ask whether rejects-units or lots discarded as substandard-are commonly included in or excluded from total output. It happens that the conventions are not uniform. In a large number of industries anything that is rejected as inferior, defective, or below standard before it is shipped or sold is not regarded as produced, whereas waste or discard in processing plants or in distributing establishments is included in total output. (For example, in fruit crops the quantities not approved for sale are excluded but the quantities spoiled in transport or at the distributors are included; steel output excludes defective lots which the steel mill regards as scrap, but includes waste and scrap at the fabricators; total paper production excludes the so called broke in paper manufacturing mills but includes the waste in paper converting mills.) Thus, it usually depends on where the quality control takes place and who does the rejecting. But, no matter whether this or any other convention of terminology is followed, it should always be possible to distinguish gross and net production and to ascertain the net output-quantity produced net of all rejected or discarded portions -or the effective supply, the schedule of quantities supplied after deducting rejected quantities. If the ratio of rejects to gross output is in any way related to changes in the latter, it is highly important not to stop the analysis with gross output. This seems to be a significant

inventions, is bound to mean much failure and disappointment. Thus Carter and Williams report that: 'It is not possible to get useful statistics for the proportion of good ideas that are rejected after applied research-in industrial laboratories that we have visited it varies between 50 and 90 per cent-but certainly the proportion is high.' Even the ideas that pass this technical test may fail to pass the economic test and may very properly be rejected at this stage." Quoted from Thomas Wilson, "Science and Industry," Lloyds Bank Review, October 1957, p. 37. It has been estimated that between 80 and 90 per cent of all patented inventions remain unused for technical or economic reasons. Cf. Peter Meinhardt, Inventions, Patents, and Monopoly, 2nd ed., London, Stevens, 1950, p. 256. Other estimates are even more pessimistic: "Perhaps 95 per cent of all patents have no commercial value at all" (Jewkes et al., op. cit., p. 106). The failure of patentees to renew their patents, in countries charging renewal fees, throws some light on this question. In - Germany before 1920,80 per cent of all patents had been allowed to lapse after six years and more than 96 per cent had been allowed to lapse earlier than after fifteen years, their maximum duration. See Robolski and Lutter, "Patentrecht," Handwörterbuch der Staatswissenschaften, 4th ed., Jena, Fischer, 1920, Vol. VI, p. 826. On the other hand a recent study of "patent use" arrives at a surprisingly high ratio of patented inventions actually used by the patentee or his assignee; but it was based on a questionnaire method, which is not usually satisfactory evidence. See Barkev S. Sanders, Joseph Rossman, and L. James Harris, "The Non-Use of Patented Inventions," Patent, Trademark, and Copyright Journal of Research and Education, 1958, pp. 1-60. 
consideration with regard to inventions for there are several strong reasons for expecting that the share of rejected inventions increases as the total output of inventions, selected plus rejected ones, increases.

The rejection of an invention may be either implicit in the failure to consider its application or explicit after hasty or thorough consideration. Such rejection may occur at many different points: the invention may not be accepted as a project for applied research and development ${ }^{13}$ it may be so accepted but dropped later at some stage during the development phase; ${ }^{14}$ it may be fully developed but rejected because it requires large-scale testing in pioneer plants, regarded as too costly and too risky; ${ }^{15}$ it may be technically ready for practical application but scrapped because it has yet to pass a market test judged to be too risky by the sales department; it may be given a market test, but fail; it may have passed all technical and market tests and still fail to be adopted in competition with other ventures that look more promising to a busy management, which cannot get around to doing all the things that might look good. At almost every one of these points in the career of an invention toward application the ratio of rejections is likely to increase as the flow of invention, in the sense of the gross total of inventions produced, is enlarged.

${ }^{13}$ There is not "any simple or uniform percentage of research results that go into development. That varies very largely from firm to firm with the origin of their research or development projects and with the ways in which potential projects are evaluated. Nevertheless many research results are not taken further, either because it seems fairly clear that it would be unprofitable to develop them, or because some must be excluded on cost grounds. The greater the cost of development, the greater the importance of exclusion. The less the attention of the research staff to the commercial significance of their projects, the greater the chance that research with great potentialities in industrial application will be excluded, if only because a man who is preoccupied with research as such will not be anxious to follow his idea on to the development staff." Carter and Williams, op. cit., p. 58.

14 "Development is a term which is loosely used in general discussion to cover a wide range of activities and purposes, but all these activities seem to satisfy three conditions. One, development is the stage at which known technical methods are applied to a new problem which, in wider or narrower terms, has been defined by the original invention. Of course, it may happen that in the course of development a blockage occurs, existing technology may provide no answers, and then, what is strictly another invention, is called for to set the ball rolling once more. Two, and consequentially, development is the stage at which the task to be performed is more precisely defined, the aim more exactly set, the search more specific, the chances of final success more susceptible to measurement than is true at the stage of invention. Invention is the stage at which the scent is first picked up, development the stage at which the hunt is in full cry. ... Three, development is the phase in which commercial considerations can be, and indeed must be, more systematically examined, the limits of feasibility imposed by the market are narrowed down." Jewkes et al., op. cit., pp. 18-19.

15 "Sometimes development consists of finding ways of producing on a large scale the same thing-or broadly the same thing - as has been produced already on a small scale. ..." Ibid., p. 199. 


\section{The Effective Supply and Cost of Inventions}

We have now reached a convenient point to bring together the major results of our analyses of the supply of inventive labor, the production of inventions, and their selection for use.

First, we discussed the supply of inventive labor, regardless of quality, and found it to be subject to increasing supply prices. Second, we looked into the supply of inventive labor capacity and were impressed with the possibility that additions to the inventive personnel will be of inferior quality. Third, we analyzed the supply of new (raw) inventions and concluded that, beyond a point, the law of diminishing returns will be operative. And fourth, we inquired into the supply of inventions selected for actual use and discovered a tendency toward a diminishing ratio of exploitation.

These findings may be formulated in the following four propositions:

1. As the total amount of compensation for inventive work increases, the amount of inventive labor is likely to increase less than proportionately.

2. As the total amount of employment of inventive labor increases, the size of inventive labor capacity (the amount of inventive labor corrected for quality) is likely to increase less than proportionately.

3. As the total amount of inventive labor capacity (the input of inventive labor of standard quality) increases, the amount of new inventions made (the output in the form of workable technological ideas) may increase less than proportionately.

4. As the total amount of new inventions increases, the amount of "effective" new inventions (inventions developed and actually put to work) is likely to increase less than proportionately.

The cumulative loss in the efficiency of incremental compensation for inventive work may be very serious. We shall show elsewhere that the four transmission losses in the transformation of social energy need not exhaust the list of possible cost items in the accelerated procurement of workable inventions.

These relationships can be expressed in the form of four supply functions--the supply of (1) inventive personnel, (2) inventive capacity, (3) new "raw" inventions, and (4) effective (worked) inventions -in terms of the prices or compensations offered, that is, as functions of the compensation paid per inventive worker, per unit of inventive labor of standard quality, per invention of standard importance, and 
per utilized invention of standard importance. Put in this form, one may state that: (1) The supply of inventive labor is unlikely to be infinitely elastic and quite likely to be relatively inelastic; (2) The supply of inventive labor capacity is probably even less elastic than the supply of inventive labor; (3) The supply of new raw inventions may, in certain circumstances, be even less elastic than the supply of inventive labor capacity; and (4) The supply of effective (worked) inventions is likely to be even less elastic than the supply of raw inventions.

Of course, it is conceivable that all four supply functions are infinitely elastic: additional inventive labor may be available at the same rate of pay and in the same quality, and new raw inventions may be produceable under constant returns and found to be eligible for application at an undiminished rate. In this case a given percentage increase in the outlay for inventive work will yield an equal percentage increase in the number of inventions selected for application. But there are four potential shrinkages of the percentage increase in yield: higher rates of pay, lower quality of the personnel, smaller output of raw inventions per input of inventive capacity, and a higher rate of rejection in the selection of inventions for use. These shrinkages are independent of one another; but they may add up with a vengeance.

\section{COMMENT}

\section{JACOB SCHMOOKLER, University of Minnesota}

I find myself in substantial disagreement with Machlup on only one point. Rossman and Sanders report finding that between 40 and 50 per cent of the inventions patented by independents and between 50 and 60 per cent of those patented by captive inventors are used commercially. Machlup rejects these findings on two grounds: (1) they were achieved by questionnaire, and (2) they disagree with other estimates, as he interprets them.

Now, so far as I know, only two actual studies have been made of the commercial use of patents: the Rossman-Sanders study and a study of patent usage by large firms conducted at the Harvard Business School. ${ }^{1}$ Both studies agree completely for firms of the same size class. Moreover, both studies are consistent with a reasonable interpretation of the record of tax payments by patentees in England and Germany where patentees must pay substantial taxes or forfeit

\footnotetext{
1 Frederic M. Scherer et al., Patents and the Corporation, Boston, 1958.
} 
their patent rights. One cannot dismiss the results of a questionnaire study merely by saying questionnaires are unreliable. One has to show how the particular study was unreliable, and this Machlup has not done.

The other estimates with which the Rossman-Sanders results conflict were armchair estimates so far as I am aware. Further, they were mainly estimates not of the proportion of patented inventions used commercially, but rather of the proportion which yielded a profit to the inventor. ${ }^{2}$

Let me comment briefly on the lines of future research which are suggested by a reading of Machlup's paper. One is the development of quantitative estimates of Machlup's aggregate supply curves. Another is the development of similar estimates of the supply curves for specific fields of invention: there is no reason really to suppose that the women who invent waterproof mattress covers are part of the same labor supply as the men who invent artificial earth satellites.

Finally, and most important of all, we need an analysis of the factors that cause shifts in the Machlupian supply curves. So far as the supply of inventions is concerned, we need to know how scientific discoveries and inventions affect the efficiency with which inventive effort is converted into inventions.

So far as shifts in the supply of inventors are concerned, there are a whole host of familiar, unsolved problems: the effect of education on originality as well as on technical proficiency; the effect of ethnic and religious influences; the existence of secular changes in risk preferences and perhaps in the very recognition of risk; the effect of the shift

\footnotetext{
${ }^{2}$ Thus, Vaughan said, "It is estimated that nine-tenths of the patents issued by the United States do not bring enough financial reward to the inventors to cover the Patent Office fees, the charges of patent lawyers, and attendant expenses" (Floyd L. Vaughan, Economics of Our Patent System, New York, 1925, p. 169). C. F. Kettering testified that less than one per cent of General Motors' patents had proved valuable (T.N.E.C. Hearings, Part 2, p. 353). On the other hand, International Harvester Company stated that it used two-thirds of its patents (Pooling of Patents, H.R. 4523, 74th Cong., 1936, p. 3412, cited in W. B. Bennett, The American Patent System, an Economic Interpretation, Louisiana State University Press, p. 188). Kaempffert declared that less than five per cent of the patents issued have paid for their government fees (Waldemar Kaempffert, "Our Defective Patent System," Outlook, 1912, pp. 548-51). Warner held that not more than one per cent of the patents issued repaid all the inventors' expenses (E. P. Warner, "The Nature of Invention," Harvard Graduates Magazine, 1923, pp. 310-17). But Thomas contended that between ten and eighteen per cent of patents are "more than reasonably profitable" (Edward Thomas, "Are Patents Worth While?" Journal of the Patent Office Society, Vol. 13, pp. 232-35). With the possible exception of the estimates of company executives relating to patents held by their own companies, these are nothing more than conjectures, and most of them relate not to use but to return received. (Italics supplied in above quotations.)
} 
from independent to hired invention, i.e. the effect of the organization of risk-bearing; and the effect of the different degrees of risk of failure for hired inventors as distinct from the risks of failure confronting, say, production engineers or college professors. 
